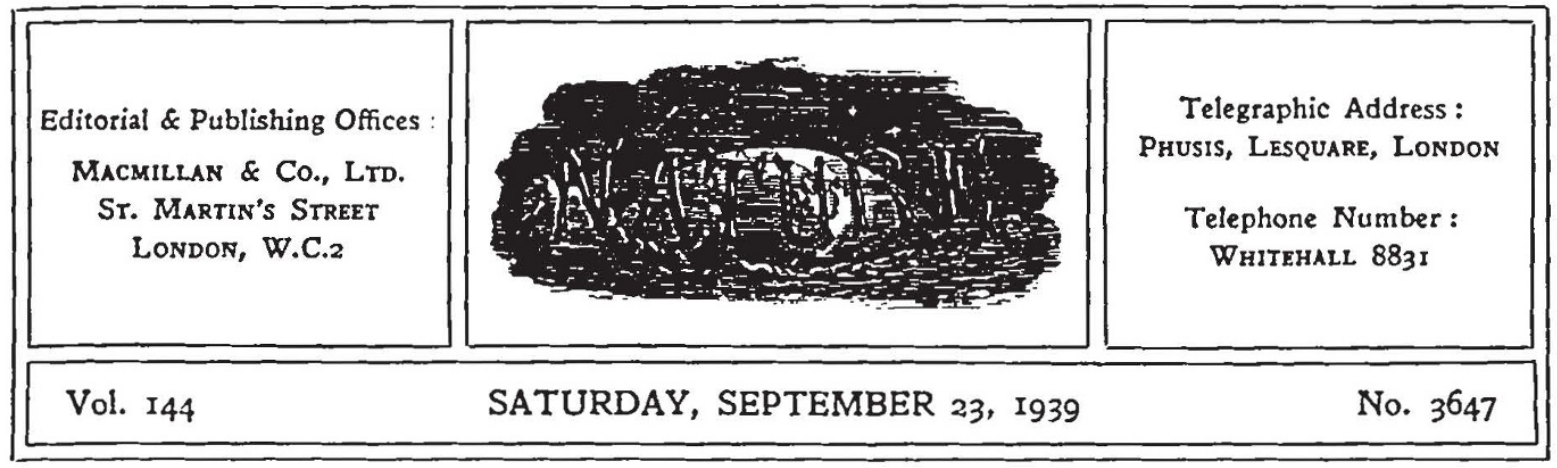

\title{
SOCIOLOGICAL ASPECTS OF EVACUATION
}

$\mathrm{T}$ WHE complaints regarding the which are being received operation of evacuation schemes in England have at least the merit of preventing any undue complacency arising from the smoothness and efficiency with which the actual transport arrangements were carried out. The success of that operation and its fortunate freedom from attack might well have engendered undue optimism and encouraged the tendency to forget that the real test of evacuation has yet to come. The problem of dispersal, however urgent as a first step in national defence, is simple compared with the more abiding social problems which evacuation presents, not only under emergency conditions but also in the permanent re-integration of national life.

It is well to recall at the start that, as Dr. 'T. Adams pointed out in his able paper at the British Association meeting at Dundee, under certain conditions, evacuation, however difficult and costly, must remain for some few cities an indis. pensable element of defence while the possibility of war remains, unless we are prepared deliberately to forgo certain of the advantages which can only be realized in a properly administered city. Accordingly it is important that the experience gained at every stage from the actual preparation and conduct of the evacuation, to arrival and settlement in the reception areas, the social problems of the eracuated areas, until the final return to and re-settlement in the eracuated areas when the emergency has passed should be carefully sifted and studied by scientific and impartial minds.

The outstanding feature of eracuation in England is indeed that it is a social experiment on a very large scale, and its success or failure will depend on the attention which is given to the social factors, and the thoroughness and impartiality with which they are investigated and handled. It should be obvious that many of the well-founded complaints which are encountered arise primarily from neglect of, or imperfect attention to, social factors in the preparation for the dispersal. Certain misfits or embarrassments were almost inseparable from a domestic re-shuffle on the existing scale. Differences of outlook and of social position must be expected and should provide no insuperable bar to domestic harmony. Different conceptions of what constitutes personal cleanliness present much more intolerable difficultics, and complaints on this score have come as freely from those acting as hosts as from evacuees who shrink from the squalor of the homes in which they have been placed.

The extent to which such complaints have been voiced is clcar evidence that something has been seriously amiss with the planning of the evacuation. Insufficient attention has been paid to the relative social types of evacuating and receiving areas. In some instances accommodation of the exact type required has been untapped while the evacuees were received into neighbouring districts under conditions which promptly stimulated a migration homewards. 'The reriest attempt at social survey or comparison of receiving and evacuating areas would have greatly reduced the proportion of misfits.

It should not, of course, be too late to remedy the worst mistakes, and indeed certain education 
authorities have taken wise and effective action. Too much stress cannot be laid on the importance alike of checking any homeward drift and of encouraging the good will betreen the evacuees and their hosts which is generally so conspicuous a feature. The value of this sympathy and understanding can scarcely be overstressed in relation to the social re-integration which lies ahead.

That is the aspect upon which attention should next be concentrated, and the reopening of the schools and derelopment of the educational organization in the reception areas is only a special aspect of this problem. Difficulties raised by such questions as equipment and buildings are of secondary importance compared with that of ensuring that the evacuated children are living in a background favourable to their development, and repairing so far as possible the damage which upheaval and separation from homes and parents and familiar surroundings may have engendered.

If it is necessary to plan for a period of three years or more, as indicated by the Government, something more than temporary expedients will be required, whether in regard to educational equipment or social background. Moreover, the drawbacks of improvisation in teaching are all the greater if the satisfaction and support which the normal home surroundings afford are lacling. Equally the social services which the derelopment of education has been rendering may be even more imperative under the conditions which obtain in the reception areas if the nation's capital in youth is not to be wasted.

'To maintain existing standards of education and well-being among children and adolescents in the conditions imposed by evacuation is no simple problem, but its solution is essential, and no exigencies of national defence can justify its neglect. Indeed, the experience of the War of 1914.18 should remind us of the danger of abandoning policies already laid down for improving those standards. It is not to be expected that no checks will be encountered or no harm done under the conditions of strain and hazard imposed on the whole nation; but there is no more vital national interest than that of seeing that the young are shielded from any untoward effects so far as possible, and the disturbance of their normal development and training minimized.

The educational problem is only one of the issues raised by evacuation, and even here there are features which may yet prove to be assets. To thousands of children from congested areas and slums a new world is opening, and the spirit of adventure in which they set out at least holds promise of an opportunity of bringing townsfolk to learn something more of the countryside and of its life which could give a ner mean. ing to some of the content of educational syllabuses. The spirit in which most people in the reception areas have accepted their responsibilities and the courage and adaptability of most adult evacuecs are other solid assets that have not only made the evacuation scheme workable but also helped to alleviate the wholesale disruption of family life entailed.

The opportunity of social re-integration must not be missed, and the good will displayed in the actual evacuation cannot be allowed to be dissipated. Steps must be taken to mitigate and to eliminate the disruption of family life so far as possible and to explore rapidly all avenues, such as the construction of rural camps which offer the prospect of terminating the separation of mothers and children. Besides this, problems of health and hygiene will demand close attention if the dangers of epidemics, especially under the stress of emergency conditions, are to be prevented or minimized, and excessive strain on health, sanitation, water supply and other public services in the reception areas avoided.

Many of these matters call for wise planning and scientific investigation; but no complete solution can be achieved if we fail to remember that the problem is a national one and not merely that of a number of independent reception areas. The evacuated areas themselves will be subjected to cconomic and social stress and strain even if fortunately spared from actual attack from the air. Not merely private households, but also general trading conditions, amenities and public services cannot but be profoundly affected if not dislocated by the removal of a high proportion of the population of an area.

The economic problems of evacuation are large and complex. No less important are those of recreation and fitness. These reach far beyond the provision of facilities for organized games for the schools in the reception areas. The existence of amenities for physical and mental refreshment is a vital factor in the psychological adjustments involved and in the maintenance of morale.

The psychological aspects of evacuation are possibly the most important of all. Neglect of them may delay the establishment of reasonably 
satisfactory conditions in reception and in evacuated areas. At the worst it may lead to deteriora. tion in morale, which by frustrating the very pur. pose of evacuation may endanger the whole national effort. The stresses set up both in evacuation and in reception areas, like those caused through the whole fabric of civil life by the necessity of re-adapting or even re-orientating life to the restrictions of morement, lighting, etc., imposed by wartime exigencies, and the strain of long hours, often with responsibilities in some branch of civil defence in addition to the working day, demand some opportunity for relief from time to time if serious physical or psychological damage is not to result.

On this ground alone the question of recreation presents problems which cannot long be neglected. Means must be found, consistent with public safety, of ensuring reasonable opportunities of entertainment and relaxation. Possibly the transfer or redistribution of such facilities in the reception areas may be involved as part of the policy of developing an adequate communal life. It should not be forgotten, however, that the migration to the reception areas has, together with the curtailment of public and private means of transport, largely closed for purposes of re. creation areas which derive most of their importance from their value as health resorts. As the war continues, the need for attention to such questions cannot but increase.

These are only some of the more immediate problems which evacuation presents. There are others equally important which will require atten. tion before the normal trend of the national life can be resumed. The dispersal of business and industrial firms as well as of Government departments and the accompanying decentralization will raise questions of policy before a return can be made to previous locations. New and unexpected opportunities of town planning and of guiding the location of industry may well present themselves, if the experience now being gained is wisely utilized. In these, as in the more immediate and pressing problems, impartial survey and patient scientific investigation of the many economic, social, technical and psychological factors involved a:e essential. Scientific workers would be unworthy of their own traditions if they failed to insist on the importance of a scientific study of the problems which evacuation presents, or to direct attention to factors which threaten to sap either the physical or the moral welfare of the nation in the task to which it is now addressed.

\section{FLUID DYNAMICS}

\section{Modern Developments in Fluid Dynamics} An Account of Theory and Experiment relating to Boundary Layers, Turbulent Motion and Wakes. Composed by the Fluid Motion Panel of the Aeronautical Research Committee and others, and edited by $S$. Goldstein. (Oxford Engineering Science Series.) Vol. 1. Pp. xxiv $+330+29$ plates. Vol. 2. Pp. xii $+331-702+$ plates $30-35$. (Oxford: Clarendon Press; Iondon: Oxford University Press, 1938.) 50s. net.

$\mathrm{T}$ $\mathrm{HE}$ present work is dedicated to the memory of Horace Lamb, the father of classical dynamics, whose fundamental work, "A Treatise of the Mathematical Theory of the Motion of Fluids", appeared in six English editions as well as in several foreign translations and is in the hands of every specialist in the theory of fluid motion. By 'classical' hydrodynamics, we understand the hydrodynamics of the nineteenth century in contrast to that of the twentieth, which is distinguished chicfly by a more detailed and at the same time extensive study of the influence of viscosity, particularly in the case of fluids of small viscosity, so that a much nearer approach to reality has been attained. Even those parts of the modern theory which are fundamental for the ideal frictionless fluid have been enriched in very important points by new research. Here, the knowledge of the existence and behaviour of surfaces of separation was effective in the discovery of new ways in which to obtain practical results.

During the last twenty years, much new knowledge, with practical applications, has matured concerning the disturbance occurring in the majority of technical fluids - of which the ultimate cause is still a problem-which is known as turbulence. These developments have proved extremely fruitful where scientific application is 